given by a single set, we fina that the best we can say for the reaction is that it makes mistakes in 5 cases out of 31 . If we believe firmly in tlue reaction, we may moke excuses for two of these five cases ( 1 and 21 ) by saying that the blood was withdrawn too soon after a meal, and we may excuse the other three palpable lapses by saying that we must have committed some error of technique, for no man is infallible, and we can the more readily accord the vice of fallibility to others than to ourselves. Judging from the large amount of other work that Abderhalden turns out of his laboratory, it is scarcely possible that he can have personally attended to the examination of the very large number of cases on which he or his assistants have reported.

Summary.

To sum up the results of the above 100 cases tested to prove the diagnostic worth of the dialysation reaction in pregnancy, we find that by the most generous reading possible, judging by two sets of experiments and not by the usual one, making allowances for all the hypothetical fallacies, we have still 17 most glaring mistakes in diagnosis, which of itself is a large percentage, sufficient to destroy the diagnostic worth of the reaction. But if we apply to the good results the same code of ethics by which we reject the undesired, then the whole theory becomes worthless.

In a second article the question of protective ferments in cancer will be considered, and the inherent fallacies of the method will be examined in detail.

1 Biochem. Zeitsch., October 23rd, 1913.

\section{Aresidentíal Addotresses}

\section{TO THE \\ BRANCHES OF THE BRITISH MEDICAL ASSOCIATION. \\ BORDER COUNTIES BRANCH. \\ NATIONAL HEALTH INSURANCE. JOHN BELL FISHER, M.D., D.P.H., WHITEHAVEN.}

In the first place permit me to express to you my best thanks for the honour you have done me in electing me President of the Border Counties Branch. It is a position I appreciate very highly. Our Association has been and is passing through troublous times. We have had dissensions within and attacks from without; a rush to join our ranks when danger threatened; withdrawals and resignatious when these same persons failed to get all their own way. Grumblings we have had in plenty, because the Association failed to secure all the advantages for the profession that these most exacting critics demandedthe critics being for the most part those who did nothing themselves either for the Association or the profession, but thought apparently that membership of the Association entitled them to be spoon-fed with benefits without any effort on their own part.

These tribulations, however, we have survived, and will survive; they should only serve to bind more closely together those who have the best interests of the profession and the Association at heart. For the interests of the profession and the interests of the Association are one, and the Association is doing its best work when it is safeguarding the interests of the profession at large and not of any particular section.

The National Health Insurance Act directly affects the great majority of the profession, and profoundly alters their relation to their patients, to the general public, and to the State. Even those who are not on the panel are bound to be affected sooner or later, for it is quite certain that this Act is only the beginning of still greater changes. Dependants will be brought within its scope; insticutional treatment cannot for long be confined to tuberculosis; our general lospitals cannot be expected to undertake the wholesale treatment of insured persons and continue to be supported by voluntary contributions. State aid or municipal aid will have to be accorded them, and this inevitably involves more or less State or municipal supervision. The Act has already checked the flow of voluntary contributions. It will doubtless continue to do so in an everincreasing degree. Where the end will be no one can tell.

Certain it is, however, that greater changes than we have yet seen will be brought about, and it behoves us to consider and anticipate these changes, so that, as far as possible, they may be so controlled and directed as to secure the best possible results for the profession and the public weal.

I believe most strongly that there is no subject of such vital importance to the profession at the present time, and none so essential to the welfare of our patients, as the establishment on a sound and just basis of the relation that is to exist in future between doctor and patient. 'That the old relation is to be changed fundamentally none can doubt. It has been altered already for some fifteen million persons, and a vast majority of the profession. The full extent of the change is not yet appreciated, but it is not the less on that account a change of the most radical lind, and whether it is to be for better or worse depends very largely on the wisdom of the course taken by the profession as a whole, and the unity and singleness of purpose with which they persist in carrying out what they con. ceive to be the best policy alike for themselves and for their patients.

We have to recognize the fact that insurance is the law of the land, and that the vast majority of the medical profession have accepted service under the National Insurance Act as it is. What I want to insist upon to-day, with all the force of which $I$ am capable, is that we are not on that account to consider that there is nothing more for the profession to do than merely go on quietly and submissively attending to the bodily ailments of our patients, leaving the arrangements for organization and control of the relations between the doctors and their patients to committees and Commissioners. It is now for the first time that the necessity has arisen for doctors to attend to their own business. Under the conditions of State insurance unless the doctors look after their own interests they will certainly suffer. The State undertakes that the insured person shall have proper medical attention, and the insured person himself expects it, and the approved societies complain that the demands on their funds are excessive. Amongst so many contending forces the doctor will fare, badly unless he can protect his own interests, and this he is absolutely nnable to do individually against such powerful influences. Let no one suppose that finality has been reached in the arrangements made for providing and paying for medical attendance, or in the conditions imposed upon doctors.

The National Insurance Act, 1911, only came into operation, so far as medical service is concerned, in January, 1913, yet an amending Act was passed during 1913, and only pressure of other business in Parliament has prevented the introduction of another amending Act in 1914.

We know that the approved sosieties are exerting their influence to secure that the next amending Act shall restore to the societies the " control of their own doctor," as they term it. We know one great reason for this to be that many of the societies have been very hard hit. The amount of sickness benefit they have been called upon to pay has greatly exceeded their estimate, and they desire the control of the doctor because they think it will enable them to influence him in the direction of giving fewer certificates of incapacity for work, and such as lie does give for shorter periods.

I think myself that both the societies and the doctors made a mistale in the first instance in attaching too much importance to this matter of control of the doctor, to the neglect of other and more important issues. When the Insurance Bill was first under discussion it was generally anticipated that the "approved societies". contemplated in the bill were the old-established friendly societies, such as the Oddfellows, Foresters, and the like, together with clubs providing medical attendance as one of their benefits in connexion with certain localities or industries. The inclusion of trade unions, and more especially of the large industrial insurance associations, amongst the approved societies has entirely altered the outlook. I thinls the objection on the part of doctors to 
$\therefore$ society control" as it previously existed was much exaggerated. Each lodge, or court, consisted of local men, who had no antipathy to doctors in general, and certainly none to the doctor of their choice-" our own doctor," as they called him. Little differences necossarily arose but the objection to "society control" was not found to exist chiefly amongst the supposed victims of a pernicious and tyrannical system, the club doctors. Rather was it a bogie raised to frighten the uninitiated by those who had no connexion with, and knew very little about, club practice. Our own Journal at one time said some very unkind things about the demoralizing effect of "contract practice" alike on patient and doctor, but these persons themselves did not seem to be aware that they stood in need of sympathy or commiseration. The advent of the large industrial insurance companies has entirely altered the conditions. Instead of having to deal with a committee of local men, mostly kindly disposed towards the doctor, we have a huge association of members whose very number prevents them having that personal lnow. ledge of one another from which sympathy and co-ordination spring-an association governed and controlled by a bureau, the constitution of which is absolutely unknown to most of the members, acting through agents who are the mere tools of the managing committee. The members know nothing of their society except as represented by the agent, the agent can only give unquestioning obedience to the instructions of the managing committee, and the managing committee is a body of business men who are guided solely by financial and statistical considerations, to whom insured persons and doctors alike are mere factors in their calculations. The element of personal knowledge and individual sympathy is entirely wanting.

That is what I mean by saying that the friendly societies and doctors alike made a mistake in making this question of control of the doctor a leading plank in their platform at a time when more important matters should have engaged their attention. For, as the matter stands at present, neither has successfully attained what was aimed at. The societies have lost their power of selecting their doctor who shall be entirely responsible to the society, and no one can pretend that "free choice of doctor" is anything more than a pious opinion in the vast majority of cases.

In the case of trade unions or similar bodies, and in pre-existing clubs, free choice of doctor is out of the question for the vast majority of the members, 'accustomed as they are to acquiesce in the views and obey the orders of their leaders.

In the future, however, this question of control, of which free choice is only one feature, is destined to be the most important that the profession will have to deal with. It may at first sight seem like putting the cart before the horse to attempt to speak about control before settling the question of free choice, for it is obvious that if there is not at least a nominally free choice of doctor-that is, if the doctor is not chosen by the individual patient, but by his society-that doctor will. be under the control of the society or the society's managers. He will have to carry out their wishes in all essential particulars, or they will change their doctor if there is another available. It is for this reason that societies so much object to free choice of doctor by the patient. They think, no doubt rightly, that if they have the legal right to engage or dismiss their doctor, the difficulty of control will be reduced to a minimum.

But first of all let us consider what is meant by " control of the doctor," as it is not very euphemistically called. It does not, or should not, mean interference in detail with the medical treatment of a patient by his doctor. But it is essential that either the societies or the State which provides the money, or administers the funds, should have some power to prevent wasteful and extravagant expenditure either in the drugs they have to pay for, or in the cash benefit they have to provide when a patient is certified unfit to follow his occupation.

How can this control be exercised in the most efficient manner and with the least possible interference with the doctor's right to do what he thinks best for his patient?

Compulsory. sickness insurance is a new thing in this country. We have had no experience of it. Our views are therefore apt to be distorted or one-sided; according to our preconceived notions. Can we learn anything from the experience of other countries in which insurance laws have been in operation long enough to show the good and bad effects of different methods, the dangers to be feared, and how these may best be avoided?

Germany has had compulsory insurance since 1884. Generally speaking, insurance against sickness has been compulsory for all manual workers except agricultural workers and domestic servants, and for some other classes of workers, such as foremen and commercial employees, if their income did not exceed $£ 100$ a year. Under the new law agricultural workers and domestic servants are included, and the income limit for other classes is raised to $£ 125$ a year.

In 1909 over $13,000,000$, or 21 per cent. of the total population, were insured against sickness. In 1885 it was 10 per cent., in 1890 it was 14 per cent., in 1895 it was 15 per cent., in 1900 it was 18 per cent., in 1905 it was 20 per cent., and in 1910 it was 22 per cent.

Sickness insurance is effected through local societies of insured persons. These societies are of several kinds, and the insured person has no choice of society; it is automatically determined for him by the locality in which he lives or works and the nature of his employment. 'The only exception is that a person who is adequately insured in a registered society-corresponding to an English friendly society-is released from other insurance, but in this case he has to pay the whole cost himself, his employer has not to contribute to the credit of such an employee.

In ordinary cases (that is, apart from these registered societies) the contributions are a percentage of the wages. The workman pays two-thirds, the employer one-third. The public authorities do not directly grant any subsidy towards sickness insurance, but they supervise the administration, and the cost of this is considerable.

The societies are self-governing. The governing bodies are directly elected by the insured persons and the employers, the number of representatives being propor. tionate to the contributions-that is, two-thirds are elected by the insured, one-third by the employers.

From what I have said it will be evident that the circumstances in Germany differ from those in England to a considerable extent, and these differences have to bo taken into account in applying the lessons of German experience to our own requirements. In the first place, free choice of doctor is not a statutory right of the patient in Germany as it is with us. The societies are left to make arrangements with the doctors as best they can; the State lays down the benefits which the societies must provide, and only interferes when it appears tbat a society or all the societies in a district have failed to carry out their legal obligations.

In 1903 a new or amending law was passed in Germany which failed to satisfy the doctors because it did not con. cede the demands which they considered reasonable. Accordingly, they resolved to adopt an independent course of action. At Cologne, in particular, the doctors, who were strongly organized, gave notice to terminate their agree. ments with the sickness societies at the end of the year. They demanded organized free choice of doctor, higher remuneration, and better conditions of service. The "Federation of Sickness Societies" in Cologne, to which were affiliated all the sickness insurance societies, proceeded to secure the services of doctors from outside Cologne, though continuing negotiations with the Cologne doctors in the hope of a peacefal settlement.

Some of these doctors from outside; on whom the societies had relied, realizing, I suppose, the actual position of affairs, refused to continue their services, despite their contracts. This led to a shortage of doctors, and complaints were made to the local supervising authority that the sickness societies were not providing a sufficient number of doctors to ensure proper and adequate treatment, as they are required by law to do. The local authority called upon the societies to provide more doctors within a very short time. The societies were unable to do so. The local authority accordingly made agreements with the organized doctors over the heads of the sickness societies for the treatment of insured persons. These agreements were made for five years, terminating at the end of January, 1909, and provided for free choice of doctor and increased remuneration. During this period the bitter feeling between the doctors and the 
sickness societies was intensified by the fact that the societies had talsen action for breach of contract against the doctors who had refused to continue their services in 1904. Before the end of January, 1909, the societies had been busy, through their federation, obtaining doctors in different parts of Germany who were willing to serve them on the terms offered, and were able to enlist a sufficient number to prevent the local authority renewing the arrangements with the organized doctors. The societies had seventy to eighty doctors, mostly imported, whilst over three hundred organized doctors refused to have anything to do with the sickness societies. With the aid of these doctors, gathered from all parts of Germany, the societies are able to carry on their operations, but it is certain that these imported doctors do not represent a high standard of professional efficiency, and the medical treatment provided for insured persons is far from satisfactory.

Such was the position at the end of last year, after thirty years of compulsory sickness insurance law. Surely it behoves us to think serionsly and act discreetly, so as to secure that, profiting by their experience, we shall not repeat their mistakes, but from the first combine in an effective organization to safeguard the interests of the protession.

During last year (1913) matters had reached such a pass that throughout Germany doctors had posted up in their surgeries notices to the effect that after the end of the year they would cease to give service under the insurance law, and that all persons requiring medical attendance would be required to pay as private patients. This course was taken partly on account of the inadequacy of the existing rates of remuneration, but chiefly, I believe, to obtain recognition of their organizations, both in the settlement of terms of service and in the exercise of control over medical service, including disciplinary measures. The doctors in Germany are now well organized. Owing to the fact that the societies are self-governing-there is no administrative authority corresponding to our County In surance Committee-the conditions differ in different localities, and the organizations of the doctors are conse quently somewhat of a local character. This has made it more difficult to secure uniformity. With us the existence of Insurance Committees and of Insurance Commissioners tends to secure uniformity, and should render easier an effective organization of the profession.

In Cologne both sides have made great sacrifices for what they consider their rights, and neither has succeeded in obtaining what they desire. It is impossible to believe that either side is absolutely blameless and the other entirely in the wrong.

The doctors, as I have said, failed to secure the insertion in the law of 1903 of the amendments which they desired, and gave notice to terminate their engagements. The societies set to work to secure doctors from outside.

The doctors wanted increased remuneration, free choice of doctor, and "better conditions of service," the last mentioned term meaning, I take it, freedom from lay control.

The societies complained that the cost of medical service was very high, that with free choice of doctor the societies could exercise practically no control over the doctors, who ordered drugs and appliances extravagantly, and gave certificates of inability to work much too freely, with the result that the cxpenses of the societies were unduly increased.

During the period that the arrangements made by the local authority over the heads of the societies were in force in Cologne and the neighbourhood it was asserted that the expenses of the societies in medical and money benefit had inrreased 49 per cent. whilst the membership had only increased a little over 21 per cent. Since the societies have resumed the appointment of doctors, and brought in those from outside, it is a remarkable and significant fact that the high level of expenditure for medical benefit attained during the compulsory period has been maintained. The service is admittedly less efficient, its cost to the societies is not diminished. The one fact that stands out prominently is that the result of combination by the doctors is the increased rate of remuneration.

But there is another side to the question. If the societies have not gained anything in the cost of meaical benefit, they have certainly effected a saving in respect of other benefits. One of the largest of the Cologne societies found its reserve fund gradually diminishing under the compulsory system (that is, when the arrangement between doctors and the local authority were in force), and in spite of increased subscriptions was getting into financial difficulties. Since the society has appointed the imported doctors, it has been able to commence the rebuilding of its reserves, whilst at the same time increasing its benefits.

These are facts which cannot lightly be set aside. The doctor, like every other expert, is impatient of lay control. Yet it is absolutely essential that some effective control should be exercised over the prescribing of expensive drugs in inordinate quantity, the giving of certificates of unfitness for work on the inost trivial pretence, the continuance of certificates of inability after the necessity for them has ceased. Inder the old friendly societies there was much less tendency on the part of the patient to get all he conld out of the societr. On the whole, the mem. bers of these societies were the more provident and thrifty men, of independent spirit, who took a pride in never having made a demand on the funds after a long membsrship. They realized, too, that after all it was their own money that they received in benefits, and that excessive and unnecessary demands on the society's funds weakened their society, the welfare of which they had deeply at heart. 'The doctor was therefore not so often asked to certify as unfit for work a person whom he thought fit, and on the comparatively infrequent occasions when he refused to certify a patient on the club he was sure of the support of the other members, who realized that he did so in the interests of the society.

Under the new conditions of National Insurance the case is different. We may not have secured free choice of doctor to the extent that is desirable, but the very persons who are most troublesome in this respect are those who know best what freedom they have under the Act. 'They know they can change their doctor' at the end of each year without having to give any reason for doing so, and the doctor knows, too, that if he is too strict in the matter of certificates of unfitness for work he will lose his popularity. and his patients will seek other more obliging practitioners. Without intending to be unduly lenient, even when he thinks that he is acting with all due stringency, the doctor may err from want of consideration of other factors than the purely medical aspects of the case. The doctor must, if lie is to do justice to the society to which the patient belongs, endeavour to look at the matter from their point of view. Approved societies consist of persons whose narrow means habituate them to a much sterner standard of life than obtains amongst many of lis private patients, and than he is himself accustomed to. And unless this fact is re. cognized; that is, if the doctor applies to these cases of insured persons the easy standards of persons in more comfortable circumstances, it is quite impossible for the societies to meet their liabilities. In the case of the old friendly societies especially (and these are deserving of the greatest consideration at the hands of the doctor), it is by the contributions of workmen who are living close to the hard realities of a strenuous life that the society is maintained. If every applicant for medical treatment is to be given a few weeks' relief from work at the expense of his club, if we are to ignore the financial side of the ques. tion altogether and give to every such applicant the consideration that is given to the opulent valetudinarian, the bankruptcy of the societies is imminent. It may seem that I am pointing out self-evident facts, and making merely general and indefinite statements that have no practical bearing. I am speaking from experience of actual cases when I say that certificates are given too often without due consideration; they are given, no deubt, with a kindly intention, with a sympathetic regard for the comfort or convenience of the particular patient, but at the same time without regard to the interests of those other persons, scarcely less requiring rest and medical treatment in the meantime and whose prospective relief when their turn comes is being frittered away in undeserved charity.

In the matter of prescribing, too, during the short experience we have had of National Insurance, it has been made abundantly evident that a very rigid system of control is necessary. 
In Germany, it will have been noticed that whenever the local supervising authority has been appealed to it is with the "organized doctors" that a contract has been maile. More and more the doctors throughout Germany have found, as time went on, the absolute necessity of organization. These organizations, at first local and tentative, have so far justified their existence and proved their value that at the end of last year (1913) it was found to be possible to secure practical unanimity throughout Germany, notwithstanding the difficulties inherent in the German system of individual control of its own affairs by every little local society.

The conflict between the organized doctors and the Sickness Society of Leipsig is equally instructive as to the value of organization, and has brought about a generally satisfactory state of things in this society, which is recog. nized as the most important in Germany. The members have free choice of doctor, and what is of the very greatest importance, the doctors are represented by a committee, which is mainly responsible for control over the doctors. Any complaint against a doctor is made to this committee, which is empowered to take such disciplinary action as may be necessary if the complaint is found to be well founded. The remuneration of the doctors is distributed through this cormittee, which examines the accounts and prescriptions and checks the extent to which doctors have certified persons as incapacitated for work, with power to fine the doctor and require him to refund any money paid to an insured person on an improper certificate. This, I think, is the best possible kind of control of medical service. The doctors as an organized body agree as to the terms on which services shall be rendered, receive and distribute the remuneration, and themselves exercise disciplinary powers independently of any lay interference.

In additin to this the Leipsig society (not the doctors' committee) employs "confidential medical advisers," as they call them, or, as we shotild say, " medical referees."

A consideration of the actual experience of Germany seems to me to be useful at the present time, in so far as it shows us what has actually occurred there. The facts revealed and difficulties encountered, it is true, are only such as might almost have been anticipated, still we are on surer ground when we can refer to actual experiences. It is an unfortunate fact that at present the vast majority of the profession in this country take very little interest in the subject of National Insurance, except in so far as it affects their own individual practice. Very few, indeed, consider its bearing on the future, or take any trouble to understand the importance of the change which is taling place.

I attended the conference at Westminster in June of the chairmen and secretaries of the various Panel Committees with the Insurance Commissioners for England, at whose invitation the conference was held, to consider "medical certification for sickness benefit under the Insurance Act and proposals for the improvement of procedure in reference thereto."

What surprised me most of all was the lack of appreciation by many of the speakers of the altered position of the doctor towards insured persons and approved societies that has been brought about by the Act, and the relation of both to Insurance Committees and the Insurance Commissioners.

Varions suggestions and arguments were advanced which would have been good in themselves as regards friendly societies before we had any Insurance Act, but which a moment's consideration showed to be absolutely inconsistent with the actual provisions of the Act. The consequence was that very little was done beyond an explanation by the Commissioners of what was expected of the doctors. A circular (marked "Confidential") had been issued to those present on behalf of the Panel Com mittees, and the different paragraphs of this circular were taken one by one, and after some discussion by the doctors and explanation by the Commissioners, mostly agreed to as they stood. The proposals in the circular were for the most part fair and reasonable, and the attitude of the Commissioners conciliatory and explanatory. What was disappointing was that, owing to the lack of appreciation of the altered conditions created by the Insurance. Act to which I have referred, some of the doctors took up so much time in futile adrocacy of methods impossible under the Act that suggestions of real value were crowded out and could not be considered.

I refer to this matter here simply as illustrating the impotence of the profession for want of co-ordination or organization. Had the doctors present prepared their case with the same care as the Commissioners there can be no doubt that it might have been presented in a much more effectual form.

It is for organization I am pleading to-day. We have seen that one amending Act has already been required. Others are to follow. In these, and in the amended Regu. lations which will be made by the Commissioners many matters of vital importance to the profession will be dealt with.

At present certification is engaging the attention of the Commissioners, who purpose to hold conferences with Panel Committees on the subject.

The following and many other subjects will have to engage the attention of the profession if it is not to be hopelessly reduced to a position of abject servility:

The payment for mileage is on a very unsatisfactory footing. The fact that there is no provision for the payment of al anaesthetist or for assistance in emergency operations;

That abortions and premature confinements are included in the capitation fee ;

That persons whose illness is due to their own misconduct are deprived of other benefits, but are still entitled to medical attendance for their capitation fee ;

That whilst we engage to attend insured persons for a capita. tion fee of 7s., deductions are made without our consent, or even in spite of our protests, for the payment of " case values" to other districts.

Then it is to be remembered that $2 \mathrm{~s} .6 \mathrm{~d}$. of the $7 \mathrm{~s}$. a head depends, not on the Act itself, but on a Treasury grant. Already there is an outcry in certain quarters that the doctors are overpaid. Unless the doctors can put forward their own claims with some authority, what assurance have we that that grant will not be reduced, or withdrawn altogether, at the end of the three years for which it was made?

One matter of real importance that has not obtained the consideration it deserves in connexion with control of the medical service is the constitution and working of the Medical Service Subcommittee under the Act-the "Complaints Committee" as it was called in the bill as originally drafted. This committee consists of three doctors, three representatives of insured persons, and an independent chairman; many matters have to be referred to it which ought to be dealt with by doctors alone. This view was strongly urged on the promoters of the bill, but was rejected. In Germany it was not provided for at first, but has been obtained by organization amongst the doctors, and doubtless if the doctors here will combine effectually they will be able in future legislation to secure that strictly medical matters shall be left to medical committees, as in the case of the Sickness Society of Leipsig to which I have referred. It is true we have the Panel Committees, and it is perhaps too soon to pronounce definitely on their actual powers and utility, but, judging from appearances at present, I am of opinion that Panel Committees are likely to be bound up in so much red tape and so much under the thumb of the Insurance Commissioners that they will have no real power to protect the interests of the profession, and will be employed simply to assist in the administration of the Act in an advisory capacity. A strong, independent, unofficial body is required to look after the real interests of the profession.

In Germany it was by organization amongst themselves that improvements in the conditions of service were at last obtained by the doctors. They first tried to regulate their conditions of service and protect their interests through the official channels. Medical councils sought to lay down the terms on which service should be rendered, and threatened penalties if compliance was not given to their directions. But this was forbidden by the Government authorities as beyond the province of the medical councils.

A society, roughly corresponding with the British Medical Association, had existed in Germany since 1873, but in 1900 another society was formed to protect the economic interests of doctors, especially against sickness societies. This is really a trade union of medical practitioners, and is described as an "aggressive fighting 
machine." It has a membership of nearly 24,000 , which is said to be over 95 per cent. of the medical practitioners in Germany who have anything to do with insurance practice.

This society tried at first to secure its ends by legislation, but after three years of failure in this direction, by a resolution passed at its annual meeting in 1903 definitely took up the methods of independent action on trade union lines. Since then the doctors' campaign is reported to be on th whole very successful. They have not got all they wanted, but have gained a great deal, both as to conditions of service and remuneration. In many cases there has been a sort of strike or boycott, such as that at Cologne, to which I have referred, and at Leipsig. As I have mentioned also a general strike was threatened last year, but this was averted, the doctors securing much of what they asked for. The method, which is only adopted in extreme cases, takes the form of refusing to treat members of insurance societies on the terms offered. Provision is made by the society for assisting doctors who suffer pecuniary loss through the strike, and in Germany, as here, appeals have been made for contributions to their war chest or guaran. tee fund. The society of organized doctors reports:

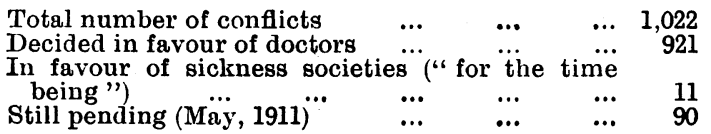

This report, dated May 1911, gives the result after twenty-seven years' experience of insurance law, during the first sixteen of which there was nothing in the nature of a trade union. Since then, of course, there has been, amongst others, the threatened general strike of last year, when the doctors won considerable advantages.

With these facts before us, surely we are not going to take sixteen years to make up our minds about the necessity of a trade union. The idea of trade unionism is not attractive to the professional mind; to many it is specially repugnant. But the whole scheme of National Insurance was distasteful to many, and the Act as passed was approved by very few of us. Yet we have accepted it and have entered into agreements to give service under it. It matters not now one iota whether that acceptance was voluntary and cordial or obtained by duress. The profession lias accepted the Act and can never repudiate it. What does remain to us is to see that the conditions it imposes on us are not made too irksome or degrading, and that we are properly remunerated for our services. Extension of the Act is certain. Dependants will come to be included and other great additions will doubtless be made.

Let us, then, once for all, make up our minds that organization is as necessary for us as it has been found, after so many wasted years, in Germany. And, whatever organization is adopted, let it be one that can be de. scribed, like the German one, as "an aggressive fighting machine."

I am not going to attempt to enter at length into the arguments as between a trust fund and a trade union That would require a lengthy address to itself, even if I were competent to explain the legal technicalities of each. But I would ask each and every one of you to think seriously over the matter. For my own part, I have no hesitation in saying that $I$ am altogether in favour of a trade union, entirely independent and, apart from the British Medical Association.

I rely on the legal opinion, which does not seem to be disputed, that only by forming a trade union can the fighting fund be protected. The funds of a trade union are free from any action for damages for any wrongful actions committed by the members in the prosecution of a trade dispute. A fighting fund which, amongst other uses, would indemnify members who suffered loss through carrying out the policy of the union, is the first necessity of any organization, and it is obviously essential to secure for such a fund the greatest possible measure of protection. This can be done, as I understand the matter, by forming a trade union, and in no other way.

A trust fund which was not a trade union, it appears to me, could have no protection, and would therefore be useless.

The suggestion that the British Medical Association should itself become a trade union is one that $I$ think wil obtain little support. The process would be beset by many difficulties, would require considerable time, and would destroy the character of the Association. The British Medical Association is a great power for good; it has a splendid record and a promising future in its own sphere, but trade unionism is not its sphere. Originally an association for the consideration of medical and scientific questions, it has considerably widened the circle of its activities, but to adopt trade unionism as its constitution would be to cripple it in all its most useful functions.

The proposal to form a trade union as a sort of branch or offset of the British Medical Association, with the Council of the Association as the governing body of the union, is even less attractive. The members of the Council are elected to their honourable position for far other qualifications than those required of the managers of a trade union. And beyond this it seems to me that there would be great difficulty in steering clear of the danger, on the one hand, of rendering the whole of the funds and property of the Association liable, in certain eventualities, for the action of the Council in restraint of trade outside the functions of the union; and, on the other hand, of their pursuing a too timorous and ineffective course of action through fear of this very catastrophe.

I sincerely hope, therefore, that the British Medical Association will itself have nothing to do with trade unionism. Let it pursue its own proper course, advocating trade unionism in its JouRNaL, advising its members for their own protection and the good of the profession to join the union, and in any other way furthering the objects of the union, but not itself having anything whatever to do with its management.

There are at present, I believe, in this country only two trade unions, registered as such-the National Medical Guild and the Leicester and Rutland Society.

There is on the agenda of the forthcoming Representa. tive Meeting a resolution, from the Altrincham Division, to instruct the Council of the British Medical Association to advise their members to join the National Medical Guild. I hold no brief for the Guild, and if a better organization can be devised, or one that would obtain more general acceptance, I should gladly support it. Meanwhile it holds the field. Its promoters deserve great credit for their prompt action in forming the Guild as an avowed trade union, at a time when trade unionism was looked upon with contempt or abhorrence by so many of the profession. Now opinion is divided between trade unionism and a trust fund; it is generally admitted that one or other is a necessity. I sincerely hope trade unionism will prevail, and if it does and becomes the accepted policy of the profession, I think the National Medical Guild deserves to be the accepted body to carry on the work which it was the first to undertake, unless, or until, a better scheme is produced. Let us remember, too, that much time would be lost in bringing any new scheme into operation. The National. Medical Guild is already constituted and doing good work with the comparatively limited means at its disposal. Much harm has already been done because the profession was not organized or prepared for the fight. The battle was lost while we were floundering about in disorder trying vainly to get into line. Let us not repeat that mistake, but make use of the organization that is ready to our hand, and not waste time and lose opportunity by accepting any new scheme of trade unionism, unless it can be shown clearly to possess very great and obvious advantages which cannot be obtained by the National Medical Guild.

NotE.-Those interested in the subject will find much useful information in MLedical Benefit in Germany and Dennark, by I. G. Gibbon, B.A., D.Sc., published by P. S. King and Son, Westminster, to which I am indebted for many of the facts concerning events in Germany.

THE tenth International Congress of Esperantists will be held in Paris in August (2nd to 10th). The Committee of Patronage includes the names of ninety-three of the leading men of France. Among the representatives of medicine are Professors d'Arsonval, Daniel Berthelot, Charles Bouchard, André Broca, Gariel, Landouzy, Charles Moureu, and Roux. During the congress the association of esperantist doctors of all nations (Tulmonda Kuracista Asocio Esperantista) will be held. 